\title{
Factors Affecting Enterprise Level Green Innovation Efficiency in the Digital Economy Era - Evidence from Listed Paper Enterprises in China
}

\author{
Zhengxia He, Wenqi Lu, Guihong Hua *, and Jianming Wang * \\ The Guidelines on Building a Market-Oriented Green Technology \\ Innovation System, which was released by China in 2019, has become a \\ powerful signal to guide the development of green technology innovation \\ (GTI). In the current digital strategy of China, the public media has become \\ a key factor for promoting the transparency of enterprise environmental \\ information. This paper measures the GTI efficiency of the listed paper \\ enterprises in China as well as incorporating media attention into the \\ research framework to explore the influencing factors of GTI of the listed \\ paper enterprises in China during the digital economy era. The results \\ showed that a positive media report had a positive impact on GTI and has \\ become a new driving factor in promoting sustainable production in the \\ digital era. Government support and openness also have a positive impact \\ on GTI. However, negative media reports, environmental regulations, and \\ technological innovation abilities have an inhibitory effect on the GTI \\ efficiency of paper making enterprises.
}

Keywords: Green technology innovation; Media attention; Tobit model; Environmental regulation; Digital economy

Contact information: Jiangsu Normal University, Xuzhou, China; hezhengxia79@163 (Zhengxia He); 1035329325@qq.com (Wenqi Lu);*Corresponding authors: huaguihong@jsnu.edu.cn (Guihong Hua); sjwjm@zufe.edu.cn (Jianming Wang)

\section{INTRODUCTION}

With the deepening of the reform and opening-up policy, China has achieved rapid economic and social development, as well as serious environmental problems. The total energy consumption of China has risen from 600 million tons of standard coal in 1978 to 4.86 billion tons of standard coal in 2019. Total carbon emissions rose from 1.45 billion tons in 1980 to 10 billion tons in 2018. The massive consumption of resources and energy leads to serious air pollution, water pollution, soil pollution, and solid waste pollution, which drastically threatens the health of the people. The paper industry is a highly polluting industry; its wastewater, chemical oxygen demand, and other pollutants discharge has always occupied the forefront of all industrial pollution. Therefore, promoting green technology innovation (GTI) to papermaking enterprises is an important step in solving the ecological and environmental problems in China. It is of great importance for China to achieve the effective utilization of resources as well as promote the coordinated development of the economy and ecology.

In January 2019, the National Development and Reform Commission and the Ministry of Science and Technology jointly issued the Guidelines on Building a MarketOriented Green Technology Innovation System, which gives a unified definition of green technology for the first time: Green technology refers to emerging technologies that reduce 
consumption, reduce pollution, improve ecology, promote ecological civilization construction, and realize harmonious coexistence between human and nature. The document pointed out that the leading position of enterprises should be strengthened, and the role of enterprises should be enhanced in terms of GTI. It can be seen that the country considers GTI extremely important. The Porter hypothesis proposes that appropriate environmental regulation can promote GTI of enterprises. However, recently it has been questioned whether environmental regulations can effectively supervise the production behavior of enterprises. In recent years, many studies have shown that environmental regulation has inhibited GTI. Wang et al. (2017a) took the industrial green water resource efficiency of 11 provinces and cities in the Yangtze River Economic Belt as the research object and found that enhanced government environmental regulation had a negative impact on the improvement of industrial water resource efficiency. The implementation of environmental regulation policies cannot be separated from supervision, but excessive government supervision may inhibit the development of enterprises. This contradiction has become one of the problems that many local governments need to urgently solve.

With the development of digital technology, the operational mode of traditional industries is undergoing great changes. The convergence of news with emerging technologies represented by big data has become the direction of the transformation of contemporary media. Advanced technology provides a new communication carrier for information, which enables the media to cover all aspects of the society and has more and more extensive information resources and audience groups. The influence of media in society is gradually increasing, and its function of spreading information and guiding public opinion has attracted the attention of academic circles. There are two main approaches in current studies to examine the influence of media on enterprise environmental responsibility behavior. The first is the supervision function from social pressure, i.e., media reports on enterprise behavior will make enterprises passively perform social responsibility under social pressure (Porter and Kramer 2006). Secondly, from the perspective of enterprise reputation, positive media reports can help enterprises establish a good image and reputation, and have a positive impact on enterprise social responsibility behavior (Xu et al. 2011). Media supervision has more and more influence on the social reputation of enterprises and has an important influence on the production and management behavior of enterprises. Numerous studies have shown that the media, as an external supervisory force, is an important means to make up for a deficiency in the legal system in terms of the supervision and management process of enterprises. Media exposure increases the possibility for relevant authorities to investigate companies that violate the rules and becomes an effective adjunct to the legal supervision system (Li and Shen 2010). Media reports on enterprises play a vital role in the public understanding and evaluating enterprises (Carroll and McCombs 2003). In recent years, many scholars have found that media supervision plays a certain role in the environmental behaviors of supervising enterprises. This study will examine if media supervision has some influence on the GTI of enterprises in the context of digital economy.

The research above shows that media attention is one of the factors that cannot be ignored when studying enterprise behavior problems. Most of the current studies on the influence of media attention on enterprise behavior have focused on the general level of enterprise environmental behavior. However, few current studies have focused on the influence of media attention on a specific enterprise environmental behavior, such as enterprise GTI behavior, which is the focus of our study. The present work intends to contribute to this research field through examining the influence of various factors, 
especially the media attention on enterprise GTI behavior in the context of digital economy era. This study intends to measure the efficiency of GTI by applying DEA-BCC model. Compared with the traditional DEA model, DEA-BCC model can further decompose the GTI efficiency into pure technical efficiency and scale technical efficiency, and can gain some new insights about the internal management of enterprises and the scale of investment in efficiency. On this basis, the authors adopted the Tobit model. The GTI efficiency was taken as the restricted dependent variable to study whether media attention has a certain impact on GTI of the listed paper enterprises in China, together with the impact of environmental regulation intensity, technical innovation ability, government support and the degree of openness on GTI. The paper is divided into five parts: introduction, literature review, methodology, results and discussion, and the fifth part is conclusions and policy implications.

\section{LITERATURE REVIEW}

Currently, more and more studies have been conducted on GTI. This study is closely related to relevant literature on the measurement of GTI and its influencing factors. These studies are primarily divided into the following four parts: Section one explores the definition of GTI; Section two explores how to measure GTI; and Sections three and four study the influence of media attention and other factors on GTI, respectively.

\section{Definition of green technology innovation (GTI)}

Green technology innovation is a kind of green evaluation definition derived from the concept of green technology and technology innovation. Brawn and Wield (1994) put forward the concept of green technology and believed that the content of green technology should cover pollution control, recycling technology, ecological technology, purification technology, detection and evaluation technology, and other aspects. Compared with traditional technological innovation, which simply pursues economic benefits and sacrifices resources and the environment, GTI includes a greater consideration to sustainable development. By establishing a coordinated management mechanism of economy, resources, and environment, producers are forced to include environmental costs into production costs, so as to improve the R \& D of green technology and ultimately achieve the purpose of environmental and resource protection (Gao and Chen 2019). In addition, venture capital can also drive enterprises to carry out GTI; it provides funds for enterprises and improves their innovation tendency, so that enterprises are not limited to short-term interests, but focus on the development of new technologies with long cycle and great potential (Qi et al. 2017). Kemp and Arundel (2002) expanded the scope of GTI, believing that GTI should include new or improved processes, technologies, systems, and products that are conducive to reducing environmental damage. It involves both technological innovation and organizational innovation. In addition to its positive impact on environmental performance, GTI plays an indispensable role in the coordinated development of enterprises and governments (Huang et al. 2019). Therefore, GTI has aroused considerable attention in academic circles. However, despite the importance of promoting GTI, enterprise participation in GTI is still lower than expected. Due to cost, risk, and other reasons, enterprises do not easily embrace innovation and remain in the 
traditional production mode (Abdullah et al. 2016). Therefore, in the traditional mode of production, embracing innovation is only for the purpose of improving production efficiency, whereas the multi-win of economic benefits, environmental benefits and enterprise competitiveness can only be realized under the production mode of green technology innovation.

Based on this, combined with the existing theories and the development goals of modern enterprises, this study believes that GTI is the extension and refinement of traditional innovation. Producers are encouraged to consider the coordinated development of economic benefits and environmental benefits through incentives and regulations to achieve the promotion of enterprise competitiveness and sustainable development at the lowest environmental cost.

\section{Measurement of green technology innovation (GTI)}

The measurement of GTI efficiency is conducted based on technological innovation. Most scholars measure the efficiency of GTI by incorporating environmental factors into the research framework. Ramanathan (2005) analyzed the production efficiency of 17 countries in the Middle East and North Africa by incorporating energy consumption and carbon dioxide emissions into input indicators using data envelopment analysis (DEA). Qian et al. (2018) included the industrial carbon emissions per unit of GDP and "three wastes" pollutants in the research framework of the two-stage green innovation efficiency and applied a two-stage relational DEA model with shared inputs to measure the green R\&D and achievements conversion efficiency of Chinese industrial enterprises. Liang and Luo (2019) included both an environmental protection index and a resource conservation index into the research framework and measured the efficiency of GTI. Feng (2013) took the energy and environmental benefits generated from the technological innovation of industrial enterprises into consideration and established a green innovation efficiency measurement model of industrial enterprises via the DEA-SBM method.

\section{The influence of media attention on green technology innovation (GTI)}

As an external supervision force, the media is an important means to make up for the deficiency of a legal system in terms of the supervision and management of enterprises. Dyck et al. (2008) believed that the media plays an important role in the dissemination of enterprise reputation information and can effectively reduce the degree of information asymmetry between external stakeholders and enterprise operation information. The development of a digital economy provides technical and material guarantee for the influence of the media on society. The frequency of public usage of the media continues to increase, and the positive or negative reporting of events by the media continues to have a stronger impact on the preferences of the social masses. Therefore, the media has an increasingly substantial influence on the behavior of enterprises in context of digital economy.

However, in addition to the supervision and exposure of media on enterprise behavior, there is also the possibility of incomplete investigation or even collusion with enterprises. From the perspective of social pressure, Porter and Kramer (2006) believed that enterprises fulfill their social responsibilities because of social pressure. However, it is difficult to predict whether enterprises really fulfill their social responsibilities in operation and management. In order to further standardize the internal operation of media 
and enhance the credibility of media, the National Press and Publication Administration issued Regulations on Strictly Preventing False News Reports in 2011, which set out detailed regulations on the standards for journalists' interviews, the internal management of news organizations and the content of news reports. The regulation calls for strengthening administrative supervision to ensure that media's investigation and report of each incident is accurate and truthful. In addition, a large number of studies have shown that media can indeed have an effective supervisory and governance role on enterprise behavior. Kong et al. (2013) found that media attention improved enterprise production efficiency and social responsibility, and significantly reduced enterprise violations. Foulon et al. (2002) indicated that the public disclosure of enterprises played a considerable role in controlling pollution emissions. Wang et al. (2017c) found that negative media reports on enterprises would improve the likelihood of investments from enterprises in terms of environmental protection. As for the reasons why media attention has an impact on enterprise operations, scholars have expounded from different perspectives. Cheng et al. (2021) argued that the effective disclosure by the media of environmental problems caused by enterprises triggers public opinion, which leads to the intervention of regulatory authorities. Additionally, the media plays a role in guiding the public opinion of investors through the capital market, influencing the stock price performance of listed enterprises, and thus influencing the decision-making behavior of the management. Zhang et al. (2016) found that media supervision, as an external supervision mechanism, can encourage listed enterprises in complying with environmental regulations, which is manifested as more active green investment behavior. To sum up, media plays an intermediary role in the transmission of enterprise information, and media reports on enterprise information play a key role in the degree of social concern and the direction of public opinion.

\section{The influence of other factors on green technology innovation (GTI)}

The traditional innovation theory represented by Schumpeter mainly emphasizes that profit is the goal pursued by enterprises. In his book The Theory of Economic Development, Schumpeter pointed out that enterprises' pursuit of excess profit is the driving force of innovation. However, innovation is not limited to a certain field. Rather, it can involve market, technology, ecological environment and many other fields. Therefore, GTI is also a kind of traditional innovation, but enterprises are required to pursue not only profits, but also ecological resources and environment. Then came the ecological modernization theory (EMT). This theory emphasizes the use of modern technology and innovation to achieve a win-win goal of economic development and environmental protection (Jänicke 2008). The theory also emphasizes four core elements to achieve a winwin goal: environmental policy, market mechanism, technological innovation, and precautionary principle (Huan and Jänicke 2010).

Cuerva et al. (2014) indicated that the environmental regulation of the government affects the GTI efficiency of enterprises. Zhu et al. (2015) believed that appropriate reward and punishment policies promoted GTI. Gu and Zhai (2014) argued that financial subsidies provided by the government could alleviate the pollution control cost pressure of enterprises undergoing GTI and compensate the external risks of R\&D and innovation. In addition, the "certification effect" from government environmental regulation, in terms of subsidized enterprises, can transmit the information to the outside world, bringing external investment (Li et al. 2018; Xing et al. 2019). Research on the impact of economic environments on GTI efficiency was conducted from the aspects of regional economic development levels and foreign direct investment. For the economic environments, in the 
new digital era, technological innovation generally appears with the following characteristics: transnational and cross-field cooperation. Liu (2019) believed that China should promote innovation in key fields and that the degree of opening to the outside world plays an important role. Cheng et al. (2020) found that the scale of the enterprise and its technology environment have an impact on GTI efficiency. Li et al. (2021) took high-tech industries as the research object and found that both the R\&D intensity within the industry and the quality of the workers had an impact on GTI. Cuerva et al. (2014) used Spanish food and beverage companies as the research object from the perspective of internal strategy. They found that internal quality management systems, environmental technology costs, and the innovation trajectory of enterprises had an impact on the GTI behavior of enterprises.

To sum up, GTI plays an important role in the production and operation activities of enterprises. Scholars have carried out abundant research on the influencing factors of GTI. Research on media attention focused on its impact on enterprise social responsibility behavior. With the development of digital technology, the change of information transmission carrier has greatly improved the influence of media reports on the public. Media reports on news events directly affect public attitudes and have a powerful role in guiding public opinion. At present, studies on the impact of media attention on GTI of enterprises (a specific enterprise social responsibility behavior) are limited and need to be further improved.

This study took the media attention outside the legal system as a supplementary element for environmental regulation policies and divided it into positive and negative reports. In addition, this study included factors, e.g., environmental regulation intensity, technological innovation ability, government support, and the degree of openness into the research framework to fully explore the influence of these factors on the GTI of enterprises in the digital economy era.

\section{METHODOLOGY}

\section{Data Envelopment Analysis-BCC (DEA-BCC) Model}

Data envelopment analysis (DEA) is a nonparametric evaluation method to measure the relative efficiency of decision making units (DMUs) while using multiple inputs and outputs. It does not consider the production technology of the DMU, but directly evaluates the efficiency of the technology benefit and scale benefit between the system and units with multiple inputs and outputs through the method of nonparametric mathematical programming. According to whether the return to scale is variable, the DEA model is divided into the CCR model with constant return to scale and the BCC model with variable return to scale. The CCR model, first proposed by Charnes et al. (1978), can be used to deal with the efficiency evaluation problem of DMUs with constant return to scale. If the enterprises cannot all operate at the optimal scale, the efficiency value evaluated via the CCR model will be affected by the scale efficiency. In this regard, Banker et al. (1984) developed the BCC model to enable the DEA method to be used to analyze production techniques with variable return to scale, and further derived pure technical efficiency and scale efficiency based on the CCR model, i.e., the comprehensive technical efficiency equals the pure technical efficiency multiplied by the scale efficiency.

The model constructed in this study is the DEA-BCC model, and its basic form is shown in Eq. 1, 


$$
\left\{\begin{array}{c}
\operatorname{Min} \theta \\
\sum_{j=1}^{n} x_{j} \lambda_{j}+S^{-}=\theta x_{0} \\
\sum_{j=1}^{n} y_{j} \lambda_{j}-S^{+}=y_{0} \\
\sum_{j=1}^{n} \lambda_{j}=1 \\
S^{-} \geq 0, \quad S^{+} \geq 0, \quad \lambda_{j} \geq 0, \quad \mathrm{j}=1,2, \ldots, \mathrm{n}
\end{array}\right.
$$

where $\theta$ represents the comprehensive efficiency value of the $j^{\text {th }}$ decision making unit (DMU), which satisfies $0 \leq \theta \leq 1$. The larger the value is, the more effective the decisionmaking unit is. $\lambda_{j}$ represents the combination ratio of the $j$ th DMU when an effective DMU combination is reconstructed according to the $j$ th DMU. $S^{-}$and $S^{+}$represent input and output relaxation variables respectively. $x_{j}$ and $y_{j}$ represent the input and output of the $j$ th DMU.

\section{Tobit Model}

This study adopts the Tobit model to explore the influencing factors of the GTI efficiency. Since the explained variable calculated by the DEA-BCC method is between 0 and 1, i.e., the explained variable is a limited dependent variable. If the ordinary least square method is applied to the model directly, then the parameter estimate will be biased and inconsistent (Greene 1981). To solve these problems, Tobin (1958) proposed a censored regression model, also known as the "Tobit Model". The standard form of the Tobit model is shown in Eq. 2,

$$
\left\{\begin{array}{c}
y_{i}^{*}=\beta x_{i}+\varepsilon_{i} \\
y_{i=} y_{i}^{*}, \text { if } y_{i}^{*} \in(0,1) ; y_{i=0}, \text { otherwise }
\end{array}\right.
$$

where $\varepsilon_{i} \sim \mathrm{N}\left(0, \sigma^{2}\right), \beta$ is the regression parameter vector, $x_{i}$ is the independent variable vector, $y_{i}^{*}$ is the dependent variable vector, and $y_{i}$ is the efficiency value vector.

\section{RESULTS AND DISCUSSION}

\section{Measurement of Green Technology Innovation (GTI) Efficiency}

In this study, the environmental expenditure of enterprises, the proportion of technical personnel to the total number of employees, and the total R\&D expenditure were selected as the input indicators of GTI efficiency. The number of patent applications and operating income were taken as outputs, which are explained in the following sections. Table 1 shows the evaluation index system of green technology innovation efficiency and Table 2 shows the descriptive statistics of each variable.

\section{Input indicators}

Scholars usually take the R \& D expenditure and the number of R \& D personnel as input indicators of innovation (Yu 2007; Sharma and Thomas 2008). Since there are no statistics on green R \& D expenditure and green innovation personnel and it is difficult to separate green innovation activities from traditional innovation activities, we refer to the study of Xiao et al. (2019) and choose traditional innovation R \& D expenditure and 
technical personnel as the Innovation input and personnel input of GTI activities. In addition, the main purpose of GTI activities is to create economic benefits while taking the reduction of environmental damage into account. We refer to the method of Zhao and Zhang (2020) and include environmental input into the research framework. We choose enterprises' environmental expenditure as environmental input, indicating enterprises' investment in pollution emission management and other aspects.

\section{Output indicators}

Scholars usually analyze innovation output from the perspective of patents, and patent output is mainly measured from two perspectives: patent quantity and patent quality. The number of patent applications is widely used to measure $\mathrm{R} \& \mathrm{D}$ efficiency and innovation, but it is not accurate to use the number of patent applications as a single indicator to measure R \& D output (Sharma and Thomas 2008). Due to competition among enterprises, the purpose of an enterprise applying for a patent is not only to make use of the patent, but also to be elected as high-tech enterprises so as to get government subsidies or enjoy lower taxes and fees and expand the market scale to gain advantages in market competition (Huang 2019). In contrast, some enterprises that develop good patents do not apply for them but use them internally to earn dividends or monopolize the market. Therefore, the number of patents alone is not an adequate indicator of output. The R \& D output of an enterprise is not fully reflected in the number of patent applications. The number of patents is usually used together with other indicators to measure R \& D output. Patent quality can be defined in two main dimensions: the economic benefits generated by patents and the legal benefits generated by the reliability of patents as enforceable property rights (Burke and Reitzig 2007). Based on this, combined with the definition of GTI in this paper, we use the operating income as a form of transformation of innovative technological achievements to measure the economic benefits of enterprise innovation.

Table 1. Evaluation Index System of Green Technology Innovation Efficiency

\begin{tabular}{|c|c|c|}
\hline $\begin{array}{l}\text { Classification of } \\
\text { Indicators }\end{array}$ & Indicators & Specific Indicators \\
\hline \multirow{3}{*}{ Input Indicators } & Environmental input & Environmental expenditure (RMB) \\
\hline & Personnel input & The number of technical personnel \\
\hline & Innovation input & R\&D expenditure (RMB) \\
\hline \multirow{2}{*}{ Output Indicators } & \multirow{2}{*}{ R\&D output } & The number of patent applications \\
\hline & & Operating income (RMB) \\
\hline
\end{tabular}

Table 2. Descriptive Statistics of Each Variable

\begin{tabular}{|c|c|c|c|c|}
\hline Variables & DMU & Mean & Min & Max \\
\hline $\begin{array}{c}\text { Environmental } \\
\text { expenditure }\end{array}$ & 120 & 36976886.3 & 262618 & 382513703.6 \\
\hline Technical personnel & 120 & 542.4 & 25 & 2250 \\
\hline R\&D expenditure & 120 & 141364942.0 & 125521 & 1017306281.2 \\
\hline Operating income & 120 & 6279900594.5 & 394217439.3 & 29472453564.0 \\
\hline Patent & 120 & 11.2 & 0 & 80 \\
\hline
\end{tabular}


Table 3 shows the changes in the GTI of 12 listed Chinese papermaking enterprises from 2009 to 2018.

Technical efficiency is the analysis of the comprehensive utilization efficiency of the input of the evaluated enterprise. When the technical efficiency is equal to 1 , it means that the environmental expenditure of an enterprise, the technical personnel, and the R\&D expenditure are fully and effectively utilized. On the contrary, less than 1 means that the environmental expenditure, technical personnel, and R\&D expenditure are not fully and effectively used. This study referred to the method proposed by Li et al. (2017) for dividing efficiency interval (the efficiency value is abbreviated as $e$ ). When $e$ equals 1 , it is considered to be completely effective; when $e$ is greater than or equal to 0.8 , but less than 1 , it is considered to be high; when $e$ is greater than or equal to 0.6 , but less than 0.8 , it is considered to be medium; and when $e$ is less than 0.6, it is considered to be low. From the perspective of the enterprise level, the overall level of efficiency is quite low. There are obvious differences in the technical efficiency among enterprises. The environmental expenditure, technical personnel, and R\&D expenditure of most enterprises have not been effectively utilized. The current input of green innovation elements has not achieved output optimization, and there is considerable room for efficiency improvement. The technical efficiency of most enterprises is in an upward trend, e.g., the technical efficiency of Shanying Paper Industry, Yueyang Paper, Sun Paper Industry, Huatai Paper, Qifeng Special Paper, C\&S Paper, and Zhongmin Energy all increase from year to year. The technical efficiency of Bohui Paper Industry has been at a high level from 2011 to 2018. The technical efficiency of Chenming Paper and Meili Paper Industry greatly fluctuates every year. In 2014, Chenming Paper even dropped to 0.311, while its enterprise scale is the largest among the 12 enterprises. It can be seen that the GTI efficiency does not completely match the scale of the enterprises. However, from 2008 to 2019, the technical efficiency of the Guitang Group and Qingshan Paper Industry was always low with subtle fluctuations. The input did not reach the optimal utilization.

Table 3. Green Technology Innovation of the 12 Listed Chinese Papermaking Enterprises from 2009 to 2018

\begin{tabular}{|c|c|c|c|c|c|c|c|c|c|c|}
\hline \multirow{2}{*}{ Enterprise } & \multicolumn{10}{|c|}{ Years } \\
\cline { 2 - 11 } & 2009 & 2010 & 2011 & 2012 & 2013 & 2014 & 2015 & 2016 & 2017 & 2018 \\
\hline Shanying & 0.377 & 0.221 & 0.223 & 0.215 & 0.189 & 0.313 & 0.481 & 0.545 & 0.6 & 0.711 \\
\hline Chenming & 1 & 1 & 0.406 & 0.51 & 0.541 & 0.311 & 0.726 & 0.479 & 0.574 & 1 \\
\hline Bohui & 0.389 & 0.574 & 1 & 0.917 & 1 & 0.853 & 1 & 1 & 1 & 0.847 \\
\hline Yueyang & 0.165 & 0.273 & 0.418 & 0.521 & 0.482 & 0.438 & 0.413 & 0.394 & 1 & 0.976 \\
\hline Sun & 0.397 & 0.515 & 0.539 & 0.632 & 0.452 & 0.46 & 0.497 & 0.506 & 0.821 & 0.694 \\
\hline Huatai & 0.392 & 0.436 & 0.545 & 0.528 & 0.536 & 0.414 & 0.542 & 0.672 & 0.657 & 0.637 \\
\hline Meili & 0.334 & 1 & 0.996 & 1 & 1 & 0.789 & 0.552 & 0.41 & 1 & 1 \\
\hline Guitang & 0.305 & 0.3 & 0.243 & 0.181 & 0.38 & 0.422 & 0.225 & 0.167 & 0.407 & 0.484 \\
\hline Qingshan & 0.225 & 0.287 & 0.304 & 0.616 & 0.287 & 0.226 & 0.233 & 0.226 & 0.203 & 0.364 \\
\hline Zhongmin & 0.131 & 0.185 & 0.157 & 0.14 & 0.298 & 0.256 & 0.753 & 0.771 & 0.934 & 1 \\
\hline Qifeng & 0.912 & 1 & 0.813 & 0.843 & 0.955 & 1 & 0.803 & 0.853 & 1 & 0.651 \\
\hline C\&S & 0.592 & 0.512 & 0.535 & 0.529 & 0.648 & 0.682 & 0.703 & 0.882 & 0.722 & 0.706 \\
\hline
\end{tabular}


Table 4 shows the changes in pure technical efficiency (GTI(tech)) of the 12 listed papermaking enterprises in China from 2009 to 2018.

Pure technical efficiency is the analysis of the management efficiency of the environmental expenditure of an enterprise, the technical personnel investment, and the R\&D expenditure of the evaluated enterprise. From 2009 to 2018, the pure technical efficiency of papermaking enterprises showed an overall upward trend. The efficiency drastically improved, and the gap gradually narrowed. The pure technical efficiency from 2015 to 2018 was generally high and has reached a relatively high level. During these four years, the average annual pure technical efficiency of the enterprise reached 0.8 , except for the Guitang Group and Qingshan Paper Industry. In 2017, the pure technical efficiency of most enterprises reached an optimal level, which indicated that the management efficiency of papermaking enterprises in recent years has reached a certain level, and the input elements have been highly utilized. From the perspective of enterprises, Chenming Paper and Bohui Paper Industry have the highest pure technical efficiency, while Guitang Group and Qingshan Paper Industry have the lowest. This may be due to the difference in the scale of the enterprises and the level of development. It can be seen from Table 3 that although the pure technical efficiency of the papermaking enterprises have reached a high level in the past four years, there is still a gap between enterprises and there is room for improvement.

Table 4. Changes in Pure Technical Efficiency (Green Technology Innovation(tech)) (GTI(tech))

\begin{tabular}{|c|c|c|c|c|c|c|c|c|c|c|}
\hline & \multicolumn{9}{|c|}{ Years } \\
\cline { 2 - 12 } Enterprise & 2009 & 2010 & 2011 & 2012 & 2013 & 2014 & 2015 & 2016 & 2017 & 2018 \\
& & & & & & & & & & \\
\hline Shanying & 0.385 & 0.403 & 0.408 & 0.4 & 0.347 & 0.385 & 0.607 & 0.841 & 0.768 & 1 \\
\hline Chenming & 1 & 1 & 0.845 & 1 & 0.891 & 0.887 & 1 & 0.738 & 1 & 1 \\
\hline Bohui & 0.391 & 0.585 & 1 & 0.919 & 1 & 0.898 & 1 & 1 & 1 & 0.918 \\
\hline Yueyang & 0.209 & 0.364 & 0.562 & 0.573 & 0.513 & 0.464 & 0.43 & 0.512 & 1 & 1 \\
\hline Sun & 0.476 & 0.72 & 0.685 & 0.846 & 0.703 & 0.819 & 1 & 0.801 & 1 & 1 \\
\hline Huatai & 0.474 & 0.557 & 0.719 & 0.62 & 0.572 & 0.996 & 0.618 & 1 & 1 & 0.868 \\
\hline Meili & 0.407 & 1 & 0.996 & 1 & 1 & 1 & 0.859 & 0.735 & 1 & 1 \\
\hline Guitang & 0.323 & 0.302 & 0.245 & 0.187 & 0.714 & 0.629 & 0.261 & 0.199 & 0.409 & 0.527 \\
\hline Qingshan & 0.225 & 0.301 & 0.317 & 1 & 0.31 & 0.237 & 0.315 & 0.278 & 0.212 & 1 \\
\hline Zhongmin & 0.131 & 0.21 & 0.227 & 0.15 & 0.312 & 0.292 & 0.986 & 1 & 0.991 & 1 \\
\hline Qifeng & 1 & 1 & 0.877 & 0.923 & 0.985 & 1 & 0.831 & 0.864 & 1 & 0.685 \\
\hline C\&S & 0.6 & 0.524 & 0.546 & 0.811 & 0.693 & 0.791 & 0.73 & 1 & 0.929 & 0.829 \\
\hline
\end{tabular}

Table 5 shows the changes in the scale efficiency (GTI(scale)) of the 12 listed papermaking enterprises in China from 2009 to 2018.

Scale efficiency is the analysis of the scale efficiency of the environmental expenditure, technical personnel, and $\mathrm{R} \& \mathrm{D}$ expenditure of papermaking enterprises, indicating whether the scale of input has reached an optimal state.

From the perspective of the enterprises, the average annual scale efficiency of 8 enterprises (Bohui Paper Industry, Yueyang Forest \&Paper, Meili Paper Industry, Guitang Group, Qingshan Paper Industry, Zhongmin Energy, Qifeng Special Paper, and C\&S 
Paper) was greater than 0.8 , which accounted for $66.67 \%$ of the total samples. There were four enterprises whose average annual scale efficiency was between 0.6 and 0.8, Shanying Paper Industry, Chenming Paper, Sun Paper Industry, and Huatai Paper, which accounted for $33.33 \%$ of the total samples. It can be seen that the input scale of the analyzed papermaking enterprises has not reached an optimal level. However, the gap between firms has narrowed. From the perspective of time, the scale efficiency of most papermaking enterprises showed a "U" shaped distribution from 2009 to 2018. In 2013, the Notice on further strengthening the Verification and accounting of the Total Emission Reduction of the Paper and printing and dyeing Industry clearly stipulated that by the end of June 2014, pulp (paper) production scale of 100,000 tons per year or more pulp and paper enterprises industrial wastewater treatment facilities must install operation management and monitoring platform, and by the end of 2015, other pulp and paper enterprises, printing and dyeing enterprises should install operation management and monitoring platform. Under the pressure of emission policy, enterprises were unable to reduce emissions through innovation activities in the short term and chose to reduce production more. As a result, efficiency was at a low point in 2014-2015. The scale efficiency of some enterprises had reached an optimal level in the earlier years but decreased in subsequent years. In recent years, several enterprises (Chenming Paper, Meili Paper Industry, Guitang Group, and Zhongmin Energy) have returned to an optimal level. The scale efficiency of a small number of enterprises did not fluctuate much, and the overall trend was relatively stable, e.g., for the Bohui Paper Industry, Qifeng Special Paper, and C\&S Paper. Generally speaking, papermaking enterprises have reached a high efficiency level in recent years.

Table 5. Changes in Scale Efficiency (Green Technology Innovation(scale)) (GTI(scale))

\begin{tabular}{|c|c|c|c|c|c|c|c|c|c|c|}
\hline \multirow{3}{*}{ Enterprise } & \multicolumn{9}{|c|}{ Years } \\
\cline { 2 - 13 } & 2009 & 2010 & 2011 & 2012 & 2013 & 2014 & 2015 & 2016 & 2017 & 2018 \\
\hline Shanying & 0.978 & 0.549 & 0.546 & 0.539 & 0.545 & 0.812 & 0.793 & 0.647 & 0.782 & 0.711 \\
\hline Chenming & 1 & 1 & 0.481 & 0.51 & 0.607 & 0.351 & 0.726 & 0.649 & 0.574 & 1 \\
\hline Bohui & 0.994 & 0.982 & 1 & 0.999 & 1 & 0.95 & 1 & 1 & 1 & 0.923 \\
\hline Yueyang & 0.792 & 0.75 & 0.745 & 0.91 & 0.94 & 0.944 & 0.96 & 0.769 & 1 & 0.976 \\
\hline Sun & 0.833 & 0.714 & 0.786 & 0.747 & 0.643 & 0.561 & 0.497 & 0.632 & 0.821 & 0.694 \\
\hline Huatai & 0.827 & 0.784 & 0.757 & 0.851 & 0.938 & 0.416 & 0.877 & 0.672 & 0.657 & 0.734 \\
\hline Meili & 0.819 & 1 & 0.999 & 1 & 1 & 0.789 & 0.642 & 0.558 & 1 & 1 \\
\hline Guitang & 0.944 & 0.994 & 0.992 & 0.969 & 0.532 & 0.67 & 0.865 & 0.839 & 0.995 & 0.918 \\
\hline Qingshan & 0.999 & 0.955 & 0.96 & 0.616 & 0.924 & 0.956 & 0.741 & 0.815 & 0.958 & 0.364 \\
\hline Zhongmin & 0.999 & 0.88 & 0.691 & 0.933 & 0.956 & 0.875 & 0.764 & 0.771 & 0.942 & 1 \\
\hline Qifeng & 0.912 & 1 & 0.927 & 0.913 & 0.97 & 1 & 0.966 & 0.987 & 1 & 0.95 \\
\hline C\&S & 0.986 & 0.977 & 0.98 & 0.652 & 0.935 & 0.863 & 0.963 & 0.882 & 0.777 & 0.852 \\
\hline
\end{tabular}

Considering the value for the above three efficiencies, the average value of the three efficiency indicators of the analyzed papermaking enterprises are: 0.58 (GTI), 0.7 $(\mathrm{GTI}(\mathrm{tech}))$, and 0.83 (GTI(scale)). This indicated that the 12 listed papermaking enterprises are at a stage of low GFI, which is limited by pure technical efficiency. 


\section{Analysis of the Influencing Factors of Green Technology Innovation (GTI)}

Table 6 shows the indicators and definition of Tobit model. In this study, the GTI, GTI(tech) and GTI(scale) calculated in the section above were taken as explained variables. For the selection of the explanatory variables, in addition to examining the influence of media attention on GTI, this paper used media attention, environmental regulation intensity, technical innovation ability, government support, and the degree of openness as explanatory variables in order to comprehensively explore the influencing factors of GTI. The Tobit model was used to explore the influencing factors of GTI. Since the GTI index calculated based on the DEA-BCC model is between 0 and 1, and there are multiple DMU in the efficiency boundary of the DEA model (i.e., the efficiency is equal to 1), in such a case where multiple samples are equal to the limit value within a specific range, a consistent estimate cannot be obtained by conventional methods. Therefore, the Tobit model is suitable to solve the problem of data blocking.

\section{Media attention (pos and neg)}

Media attention was measured by the number of times the listed papermaking companies were reported in newspapers and on the internet, according to the statistics in the CNRDS database. The newspaper media attention covered more than 400 important newspapers and periodicals, including mainstream financial and economic newspapers as well as national newspapers. The network media attention covered nearly 500 network media, including mainstream financial and economic websites, national websites, local websites, and industry websites. It was divided into positive news report (Pos) and negative news report $(\mathrm{Neg})$.

\section{Environmental regulation intensity (ER)}

For the measurement of the intensity of environmental regulation, there are primarily three different perspectives in academia: (1) From the perspective of environmental regulation policies, Smarzynska and Wei (2001) argued that legal policy treaties reflect the actual progress made by laws in terms of reducing pollution emissions; (2) Yuan and Xie (2016) measured the intensity of environmental regulation from the perspective of pollution treatment costs; and (3) Cole and Elliott (2003) used the ratio of environmental pollutant emissions to total output value to measure the intensity of environmental regulation from the perspective of pollution intensity.

Referring to the method of Yuan and Xie (2016), this study used the ratio of environmental protection expenditure to operating income of papermaking enterprises to measure the intensity of environmental regulation. The higher the proportion of environmental protection expenditure to operating income of enterprises, the higher the intensity of environmental regulation.

\section{Technical innovation ability (TIA)}

The technology innovation ability of enterprises is the most basic factor that affected GTI ability. The improvement and innovation of traditional technology can reduce the production cost of enterprises, improve the economic benefits, and improve the resource utilization efficiency of enterprises. Scholars usually use R\&D expenditure and scientific research expenses to measure the technological innovation ability (Sun and Wang 2014). Some scholars regarded the research business expenditure (Guo 2019) and the number of scientific and technological personnel (Sharma and Thomas 2008) as the 
measurement indexes. This study used the number of technical personnel in papermaking enterprises to measure the technical innovation ability of enterprises.

\section{Government support (Sub)}

The Ministry of Finance of China issued the Accounting Standards for Business Enterprises No. 16 - Government Subsidies report in 2017, which divided government subsidies into two types: (1) Government provides asset-related subsidies to enterprises for the purchase and construction of long-term assets; and (2) Government subsidies related to income MOF (2017). This is used for compensating the relevant cost expense or loss that the enterprises have produced.

In this paper, the government support index indicated the government support for enterprise GTI. Enterprises are encouraged to spend money on green technology R\&D, which are asset-related government grants, measured by environmental protection subsidies that enterprises received from the government.

\section{The degree of openness (Open)}

Scholars usually measure the degree of openness to the outside world from the following two perspectives: (1) The level of trade liberalization, which refers to a gradual reduction of restrictions on the importing of goods and services. Liu et al. (2019) used the proportion of the total import and export volume of each region in the GDP over the years to measure the degree of openness of each region and examined its influence on the green product innovation of enterprises. $\mathrm{Xu}$ (2017) used the ratio of the total import and export volume to the total industrial output value to measure the degree of economic openness in different regions and studied its influence on the GTI efficiency of industrial enterprises. (2) Foreign direct investment. Scholars usually use foreign investment directly (Gao and Huang 2017), or based on the availability of data, they adopted the gross output value of foreign-invested enterprises (Jing and Zhang 2014; Kuang and Lu 2019) indirectly to examine the impact of openness on GTI.

Since the data related to foreign investment was not available in the published annual reports, this study measured the degree of openness of papermaking enterprises from the perspective of the level of trade liberalization by the proportion of overseas business income to total operating income.

The linear regression equation for the factors affecting the green technology innovation efficiency of enterprises was established as shown in Eq. 3 through Eq. 5,

$$
\begin{aligned}
& \mathrm{GTI}_{\mathrm{i}, \mathrm{t}}=\alpha_{1} \operatorname{Pos}_{\mathrm{i}, \mathrm{t}}+\alpha_{2} \mathrm{Neg}_{\mathrm{i}, \mathrm{t}}+\alpha_{2} \mathrm{ER}_{\mathrm{i}, \mathrm{t}}+\alpha_{3} \mathrm{TIA}_{\mathrm{i}, \mathrm{t}}+\alpha_{4} \mathrm{Sub}_{\mathrm{i}, \mathrm{t}}+ \\
& \alpha_{5} \text { Open }_{i, t}+\mathrm{C}+\varepsilon_{\mathrm{i}} \\
& \text { GTI(tech })_{i, t}=\alpha_{1} \text { Posi }_{i, t}+\alpha_{2} \text { Neg }_{i, t}+\alpha_{2} \text { ER }_{i, t}+\alpha_{3} \text { TIA }_{i, t}+\alpha_{4} \text { Sub }_{i, t}+ \\
& \alpha_{5} \text { Open }_{i, t}+\mathrm{C}+\varepsilon_{\mathrm{it}} \\
& \text { GTI(scale })_{i, t}=\alpha_{1} \text { Posi }, t_{1}+\alpha_{2} \operatorname{Neg}_{i, t}+\alpha_{2} \text { ER }_{i, t}+\alpha_{3} \text { TIA }_{i, t}+\alpha_{4} \text { Sub }_{i, t}+ \\
& \alpha_{5} \text { Open }_{i, t}+\mathrm{C}+\varepsilon_{\text {it }}
\end{aligned}
$$

where GTI, GTI(tech), and GTI(scale) are explained variables; Pos, Neg, ER, TIA, Sub and Open are explanatory variables; $i$ and $t$ represents the corresponding value of the enterprise $\mathrm{i}$ in the $\mathrm{t}$ year; $\mathrm{C}$ is a constant term; $\alpha$ is the coefficient to be estimated, and $\varepsilon$ is the random disturbance term. 
Table 6. Variables and their Definitions in Tobit Model

\begin{tabular}{|c|c|c|}
\hline Variables & Symbol & Variable definitions \\
\hline Technical efficiency & GTI & Calculated by DEA-BCC model \\
\hline Pure technical efficiency & GTI(tech) & Calculated by DEA-BCC model \\
\hline Scale efficiency & GTI(scale) & Calculated by DEA-BCC model \\
\hline Positive news report & Pos & $\begin{array}{l}\text { The number of positive news about enterprises in more } \\
\text { than } 400 \text { major financial and national newspapers and } \\
\text { nearly } 500 \text { online media included in the CNRDS } \\
\text { database }\end{array}$ \\
\hline Negative news report & Neg & $\begin{array}{l}\text { The number of negative news about enterprises in more } \\
\text { than } 400 \text { major financial and national newspapers and } \\
\text { nearly } 500 \text { online media included in the CNRDS } \\
\text { database }\end{array}$ \\
\hline $\begin{array}{c}\text { Environmental regulation } \\
\text { intensity }\end{array}$ & ER & $\begin{array}{l}\text { Environmental protection expenditure / Operating } \\
\text { income }\end{array}$ \\
\hline Technical innovation ability & TIA & Number of technical personnel \\
\hline Government support & Sub & $\begin{array}{l}\text { Government subsidies to enterprises for environmental } \\
\text { protection }\end{array}$ \\
\hline The degree of openness & Open & Overseas business income/operating income \\
\hline
\end{tabular}

Table 7. Results of the Tobit Regression

\begin{tabular}{|c|c|c|c|}
\hline Variable & $(1)$ & $(2)$ & $(3)$ \\
\hline Pos & $0.0007^{* * *}(3.18)$ & $0.0009^{* * *}(2.81)$ & $0.0001(0.85)$ \\
\hline Neg & $-0.0015^{* *}(-2.37)$ & $-0.0016^{*}(-1.86)$ & $-0.0005(-1.29)$ \\
\hline ER & $-12.0999^{* * *}(-4.65)$ & $-13.6091^{* * *}(-3.98)$ & $-4.4199^{* * *}(-2.62)$ \\
\hline TIA & $-0.0003^{* * *}(-3.21)$ & $-0.00005(-0.43)$ & $-0.0002^{* * *}(-4.55)$ \\
\hline Sub & $4.40 \mathrm{e}-09^{* * *}(3.93)$ & $2.49 \mathrm{e}-09^{*}(1.68)$ & $2.82 \mathrm{e}-09^{* * *}(3.87)$ \\
\hline Open & $1.6352^{* * *}(2.90)$ & $2.4110^{* * *}(3.12)$ & $0.0102(0.03)$ \\
\hline Constant & $0.6516^{* * *}(15.52)$ & $0.6660^{* * *}(11.74)$ & $0.9914^{* * *}(36.17)$ \\
\hline Pseudo $R^{2}$ & 0.8206 & 0.3955 & -2.1601 \\
\hline
\end{tabular}

Note: Superscript ${ }^{*},{ }^{* *}$, and ${ }^{* * *}$ indicate a significance level of $10 \%, 5 \%$, and $1 \%$, respectively. The values in parentheses are the $t$-values.

The estimation results of the Tobit regression model are shown in Table 7. According to the regression results, the influence of each variable was analyzed as follows:

(1) The positive media reports on enterprises (Pos) had a positive and significant impact on the GTI of enterprises, which meant that the media reports highlighting the positive behaviors of enterprises can encourage enterprises to continue to carry out green technology innovation. On the contrary, negative news (Neg) did not promote the GTI of enterprises but had a negative impact. This conclusion provides a new perspective for the ecological modernization theory. In the management of enterprise GTI behavior, the target can be achieved not only through government policies and regulations, but also through the media, and this way is more flexible. This was also a new finding, as it was previously thought that media played a supervisory and governance role outside the legal system for enterprises, achieving the effect of regulating the internal governance of enterprises by increasing the reputation cost of the implementation of misconducts (Alexander et al. 
2008). Yang et al. (2017) mentioned the "market pressure hypothesis" in their study, stating that more negative media reports will create huge short-term performance pressure on managers. Due to the fact that once there is a short-term performance decline or innovation failure, it would be reported by additional media sources to a greater extent and arouse social attention, which would eventually lead to short-sighted enterprise managers and cause a reduction in innovative investment projects with high risk but high reward. Traditional environmental regulation policies had set strict pollution emission standards for enterprises, and the promulgation of these policies has labeled the paper industry as "high pollution" by the public. Due to the pressure of negative media coverage and negative public attitudes, business managers have given up on high-risk but profitable green technology innovation projects. Therefore, these enterprises need positive public praise as encouragement, and positive news reports to guide public opinion, so that the public can have a new understanding of traditional polluting enterprises and stimulate the GTI of enterprises.

(2) The strengthening of environmental regulation (ER) by the government did not promote an improvement in green innovation efficiency of papermaking enterprises, and the regression coefficient was negative and significant. Gray and Shadbegain (1993) showed that the development funds of green technologies in enterprises were attributable to production costs. When regulation is measured by cost, there is a strong link between regulation and productivity, i.e., enterprises with more policy constraints have significantly lower productivity levels and production growth rates. Currently, the environmental regulation on paper industries in China is primarily command-and-control, gradually transforming to market-oriented and voluntary environmental regulation policies $(\mathrm{He}$ 2017). In most cases, enterprises were passively pressured to comply with command-andcontrol policies to take environmental behaviors, and primarily relied on the government to issue policies to compulsively restrict the paper making enterprises to take environmental behaviors, so as to achieve the environmental goals of the government. In the face of the emission constraints stipulated by the mandatory policy, it took a long time for enterprises to carry out green technology research, which could not achieve the qualified effect of energy utilization rate and pollution emission in the short term. Therefore, in most cases, enterprises chose to reduce production to meet the emission standards. Shen (2012) pointed out that strengthening environmental regulation can effectively control the pollution emission behavior of enterprises, but it will also lead to an increase in pollution control costs. This determines that the "innovation compensation" effect of environmental regulation lags behind the negative effect generated by the "compliance cost", and thus fails to achieve the effect of promoting GTI in papermaking enterprises in the short term (Zhang et al. 2015).

(3) The coefficient of technological innovation ability (TIA) was negative and significant, indicating that the number of technical personnel in paper making enterprises had a significant inhibitory effect on GTI. This conclusion is contrary to most studies but was consistent with the conclusion of Li and Zeng (2020), Brunnermeier and Cohen (2003), and Xiao et al. (2015). Some enterprises were reluctant to devote funds and personnel to environmental $\mathrm{R} \& \mathrm{D}$, for fear that once new technologies are developed, they will reduce the regulatory burden and regulators will gradually raise standards (Brunnermeier and Cohen 2003). However, Xiao et al. (2015) argued that large scale enterprises tend to absorb more technical talents, because of the lack of effective incentive and management mechanisms. As such, long-term unchanged R\&D management systems lead to internal bureaucratic and corruption, and they reduce the enthusiasm of technical personnel. Thus, 
resources cannot be fully utilized. In addition, according to the DEA model above, the GTI efficiency of paper industries in China is at a stage of low efficiency, which is limited by technical efficiency. After a large number of technical personnel were input, the output efficiency of many papermaking enterprises remained low, indicating the existence of a technical personnel redundancy.

(4) The increase in government environmental protection subsidies (Sub) to enterprises was conducive to the improvement of the GTI efficiency of enterprises. Since it takes a long time for enterprises to conduct $R \& D$, short-term capital investments may not immediately bring high returns, which led to certain operational risks. Government subsidies reduce the risk of technological innovation by enterprises and as such reduces the cost of the technological $R \& D$ process, enabling enterprises to smoothly carry out $R \& D$ projects, and improve the GTI efficiency of the industry (Bai 2011). In addition, the governmental environmental protection subsidy policy could better reflect the emphasis of the local government on environmental quality improvement, which encourages enterprises to carry out green environmental protection, energy conservation, and emission reduction activities, as well as increase innovation and $\mathrm{R} \& \mathrm{D}$ ( $\mathrm{Li}$ and $\mathrm{Yu} 2016$ ). In addition, the use of environmental protection funds provided by the government to enterprises is supervised by relevant departments and is more targeted for the improvement of environmental problems (Guo 2019).

(5) The degree of openness (Open) had a positive and significant effect on GTI efficiency, which indicated that trade liberalization promotes the growth of GTI efficiency in China. The higher the degree of openness, the more conducive to attracting foreign investment and providing financial support for GTI activities in enterprises (Chen 2018). Moreover, in a relatively open economic environment, it can promote the exchange of technical experience at home and abroad, which is conducive to the introduction of foreign high-level technical talents, FDI, and other innovative elements, making it easier for enterprises to obtain an international spillover effect and improve their own green innovation ability.

\section{CONCLUSIONS AND POLICY IMPLICATIONS}

\section{Conclusions}

Sustainable development has attracted worldwide attention, and media attention has become an emerging and effective tool for promoting green technology innovation (GTI) in the context of digital economy. As such, it provides guidance for the correct public opinion to encourage enterprises to pay attention to the development of GTI and makes up for the shortcomings of traditional environmental regulations. This study is an expansion and enrichment of the general technological innovation theory and ecological modernization theory (EMT) under the background of digital economy. The development of digital technology has derived many new media, which can be applied to ecological protection. Therefore, this paper took media attention into the research framework of EMT and the general technological innovation theory to examine whether public opinion pressure caused by media attention have an impact on GTI behavior of enterprises. Overall, this study took the listed Chinese papermaking enterprises as the research object, measured the GTI efficiency of these papermaking enterprises, and further explored the driving factors and restraining factors of GTI efficiency in the digital economy era. 
1. Although the overall efficiency level of paper making enterprises has improved in recent years, the GTI of most paper making enterprises still has been at a low level during the investigation period. A good ratio between environment, personnel, innovation input, innovation output, and economic output has not been achieved. There is still great potential for the development of a business model that can realize higher GTI efficiency.

2. Media attention plays an important role in promoting the development of GTI. Positive media reports, government support, and openness have a positive impact on GTI efficiency. However, negative media reports, environmental regulations, redundant talents, and low technical efficiency inhibit the GTI efficiency of paper enterprises.

\section{Policy Implications}

To improve the efficiency of GTI in China's paper industry, the following policy initiatives are proposed:

\section{Government, society and enterprises promote GTI jointly.}

The government can use the media's role of supervision outside the law and use the public opinion to realize the governance of environmental pollution behavior of enterprises to guide enterprises to change from passive green innovation in the early stage under the pressure of regulatory policy and public opinion to active green innovation in order to gain a good social reputation. Governments can use positive and negative reports rationally to guide the public opinion in the right direction to restrain the pollution behavior of enterprises and form a virtuous circle of "government, society, and enterprises".

Media should take digital transformation as their development direction, strengthen cooperation with the Internet, and explore innovative development models under the digital era. Making full use of various digital communication technologies such as live broadcasting, Augmented Reality, Virtual Reality, and other technologies to promote the innovation of information communication, build high-quality digital media industry and enhance the social influence of media (Chen and Jiao 2020). At the same time, the media should use the positive and negative news reasonably to guide public opinion in the right direction and form the pressure and motivation of enterprises' green innovation behavior.

Enterprises should give priority to GTI projects in the process of production and operation, and consider economic benefits and environmental benefits. In the era of increasingly transparent information, it is necessary to fully disclose enterprise environmental information and innovation achievements, spread positive information to the public, establish a good enterprise image, and realize the transformation from "abiding by government environmental regulation passively" to "carrying out GTI actively in order to obtain a good image".

2. Digital technology can be adopted by the media to promote media convergence and build public opinion ecology.

Media convergence and public opinion ecology are the key contents of the construction of a government. The digital era of China means that enterprise operation will be more transparent, and the influence of the media and the public on the management of enterprises will also increase (Wang et al. 2017b). Therefore, the media should first establish their prestige and guarantee the credibility of information. New media can improve the degree of enterprise environmental information disclosure through digital technologies such as mobile Internet application technology, information visualization 
technology, and use microblog or other applications to keep the public informed of environmental information. In addition, the media can improve public participation by allowing the public to report environmental issues anonymously through online platforms. As a mandatory legal system, environmental regulation policy is indispensable in restricting enterprise pollution discharge. As a supervisory tool outside the legal system, media can obtain enterprise information through a variety of channels and play a bridging role between enterprises, government, and society.

3. Establish a talent incentive mechanism to avoid talent redundancy.

According to the results, the input-output efficiency shows that the technical personnel in enterprises have low efficiency, which leads to a negative impact from the technical personnel input on the GTI efficiency of enterprises. The findings showed that listed papermaking enterprises did not make full use of technical personnel in terms of $R \& D$, resulting in low $R \& D$ efficiency and redundancy in technical personnel. Therefore, it is important for enterprises to establish a reward system for teams with scientific achievements to promote $R \& D$ output. The enterprises should improve staff mobility, implement the end elimination system, and prevent the phenomenon of insufficient R\&D enthusiasm throughout the technical personnel within an enterprise. At the same time, technical departments should refine the research direction of talents, fully tap green technology talents, promote industry-university-research cooperation and ensure the efficient output of GTI achievements.

4. The implementation of flexible environmental regulation.

During the period of promoting enterprise technology $\mathrm{R} \& \mathrm{D}$, the government should avoid the single use of command-and-control environmental regulation policies as well as blindly increasing the intensity of environmental regulation to prevent the inhibition of enterprise innovation enthusiasm. The standards should be adjusted to a reasonable level in time, so that environmental regulations can play a continuous stimulating role. The goal is to avoid being limited to a fixed standard, and as a consequence lagging behind the development of technology. At the same time, the government should pay attention to optimizing the forms of environmental regulation, and flexibly implement them in parallel via means of emission trading, tax subsidy mechanisms, and voluntary regulatory policies. The flexible regulation mode combining various forms not only can meet the standards of environmental regulation, but also promote enterprises to carry out GTI projects, and gradually transform the negative effect of "compliance cost" behavior in enterprises under traditional environmental regulation into the positive effect of "innovation compensation" under flexible environmental regulation (Porter and Linde 1995).

\section{ACKNOWLEDGMENTS}

The authors gratefully acknowledge the financial support of The National Social Science Fund of China(19BJL033). 


\section{REFERENCES CITED}

Abdullah, M., Zailani, S., Iranmanesh, M., and Jayaraman, K. (2016). "Barriers to green innovation initiatives among manufacturers: The Malaysian case," Review of Managerial Science 10(4), 683-709. DOI: 10.1007/s11846-015-0173-9

Alexander, D., Natalya, V., and Luigi, Z. (2008). "The corporate governance role of the media: Evidence from Russia," The Journal of Finance 63(3), 1093-1135. DOI: 10.1111/j.1540-6261.2008.01353.x

Bai, J. H. (2011). "Are government R\&D subsidies efficient in China? Evidence from large and medium enterprises," China Economic Quarterly 10(4), 1375-1400. DOI: 10.13821/j.cnki.ceq.2011.04.009

Banker, R. D., Charnes, A., and Cooper, W. W. (1984). "Some models for estimating technical and scale efficiencies in data envelopment analysis," Management Science 30(9), 1078-1092. DOI: 10.1287/mnsc.30.9.1078

Brawn, E., and Wield, D. (1994). "Regulation as a means for the social control of technology," Technology Analysis and Strategic Management 6(3), 498-504. DOI: 10.1080/09537329408524171

Brunnermeier, S. B., and Cohen, M. A. (2003). "Determinants of environmental innovation in US manufacturing industries," Journal of Environmental Economics and Management 45(2), 278-293. DOI: 10.1016/S0095-0696(02)00058-X

Burke, P. F., and Reitzig, M. (2007). "Measuring patent assessment quality-Analyzing the degree and kind of (in)consistency in patent offices' decision making," Research Policy 36(9), 1404-1430.

Carroll, C. E., and McCombs, M. (2003). "Agenda-setting effects of business news on the public's images and opinions about major corporations," Corporate Reputation Review 6(1), 36-46. DOI: 10.1057/palgrave.crr.1540188

Charnes, A., Cooper, W. W., and Rhodes, E. (1978). "Measuring the efficiency of decision making units," European Journal of Operational Research 2(6), 429-444. DOI: 10.1016/0377-2217(78)90138-8

Chen, J. X., and Jiao, J. X. (2020). "The adaptation and transformation of China's mainstream media in the digital age: A case study based on five central mainstream media," Journal of the Party School of the Central Committee of the C.P.C.(Chinese Academy of Governance) 24(04), 89-96.

Chen, Y., and Liu, L. (2019). "Research on the influence of environmental regulation intensity and enterprise scale on the quality of technological innovation," Science \& Technology Progress and Policy 36(16), 84-90.

Chen, Z. Q. (2018). The Study on the Green Innovation Efficiency of Industrial Enterprises in the Yangtze River Economic Belt, Master's Thesis, Central China Normal University, Wuhan, China.

Cheng, B., Xu, Y. P., and Lin, M. H. (2021). "The corporate governance effect of media supervision: Based on the perspective of corporate tax avoidance behavior," Journal of Audit \& Economics 36(2), 105-115.

Cheng, Q., He, X., and Li, B. (2020). "Green technology innovation efficiency and its influencing factors: Empirical study based on 35 industries in China," Journal of Central South University (Social Sciences) 26(2), 97-107.

CNRDS. Chinese Research Data Services Platform. (https://www.cnrds.com/Home/Index\#/AllDatabase) 
Cole, M. A., and Elliott, R. J. R. (2003). "Do environmental regulations influence trade patterns testing old and new trade theories," World Economy 26(8), 1163-1186. DOI: 10.1111/1467-9701.00567

CPA. (2013). "Notice on further strengthening the verification and accounting work of total emission reduction of paper making and printing and dyeing industry," China Paper Association, (http://www.chinappi.org/pols/20131203151415623697.html)

Cuerva, M. C., Triguero-Cano, Á., and Córcoles, D. (2014). "Drivers of green and nongreen innovation: Empirical evidence in Low-Tech SMEs," Journal of Cleaner Production 68(2), 104-113. DOI: 10.1016/j.jclepro.2013.10.049

Dyck, A., Volchkova, N., Zingales, L. (2008). "The corporate governance role of the media: evidence from Tussia," Journal of Finance 63(3):1093-1135.

Feng, Z. (2013). "Research on industrial enterprises' green innovation efficiency in China - Based on provincial data by a DEA-SBM approach," Forum on Science and Technology in China 22(2), 82-88.

Foulon, J., Lanoie, P., and Laplante, B. (2002). "Incentives for pollution control: Regulation or information?" Journal of Environmental Economics and Management 44(1), 169-187. DOI: 10.1006/jeem.2001.1196

Gao, X., and Chen, J. (2019). "Promoting green development with green technology innovation," Guangming Daily, December 17, 2019.

Gao, X., and Huang, J. (2017). "Degree of opening to the outside world, market-oriented process and provincial government efficiency in China: An empirical study based on Malmquist-Luenberger index," International Economics and Trade Research 33(10), 19-35.

Gray, W. B., and Shadbegain, R. J. (1993). Environmental Regulation and Manufacturing Productivity at the Plant Level (Working Paper No. 4321), National Bureau of Economic Research, Cambridge, MA.

Greene, W. H. (1981). "On the asymptotic bias of the ordinary least squares estimator of the Tobit model," Econometrica 49(2), 505-513. DOI: 10.2307/1913323

$\mathrm{Gu}, \mathrm{Q}$., and Zhai, S. (2014). "Financial constraints, R\&D investment and funding sources: the perspective of R\&D heterogeneity," Science of Science and Management of S. \& T. 35(3), 15-22.

Guo, J. (2019). "The effects of environmental regulation on green technology innovation -Evidence of the porter effect in China," Finance \& Trade Economics 40(3), 147160.

He, Z. X. (2017). Study on Influential Factors and Their Mechanism of Action on Corporate Environmental Behavior, Ph.D. dissertation, Nanjing Forestry University, Nanjing, China.

Huan, Q. Z., and Jänicke M. (2010). "Theory of ecological modernization: Retrospect and prospect," Marxism \& Reality 2010(1), 175-179.

Huang, Y. K. (2019). On Quality Control of Patent Invalidation Procedure, Master's Thesis, Guangxi University, Guangxi, China.

Huang, Z., Liao, G., and Li, Z. (2019). "Loaning scale and government subsidy for promoting green innovation," Technological Forecasting \& Social Change 144, 148156. DOI: 10.1016/j.techfore.2019.04.023

Jänicke, M. (2008). "Ecological modernization: New perspectives," Journal of Cleaner Production 16(5), 557-565. 
Jing, W., and Zhang, L. (2014). "Environmental regulation, economic opening and China's industrial green technology progress," Economic Research Journal 49(9), 3447.

Kemp, R., and Arundel, A. (2002). "Survey indicators for environmental innovation," in: Proceedings from the Towards Environmental Innovation Systems, 27-29 September, Garmish-Partenkirchen, Germany.

Kong, D. M., Liu, S. S., and Ying, Q. W. (2013). "The role of media in corporate behavior: Encouraging or encouraging?” Management World 2013(07), 145-162.

Li, G., Li, Y., and Quan, J. (2018). "Environmental regulation, R\&D investment and enterprises' green technological innovation capability," Science of Science and Management of S. \& T. 39(11), 61-73.

Li, J., Li, N., and Yuan, Q. (2021). "Study on the spatial-temporal differences and influencing factors of green innovation efficiency in high-tech industry," Forum on Science and Technology in China 30(4), 92-101.

$\mathrm{Li}, \mathrm{N}$., and Yu, J. (2016). "Influence of government environmental policy on enterprises' technological innovation," World Sci-Tech R\&D 38(5), 932-936, 954. DOI: 10.16507/j.issn.1006-6055.2016.05.002

Li, P., and Shen, Y. (2010). "The corporate governance role of media: Empirical evidence from China," Economic Research Journal 45(4), 14-27.

$\mathrm{Li}, \mathrm{Q}$. (2010). "A study on the technological innovation efficiency of small and mediumsized enterprises in China based on DEA method - A case study of small and medium-sized listed companies in Shenzhen stock exchange," Science and Technology Management Research 30(10), 43-45.

$\mathrm{Li}, \mathrm{X}$., and Zeng, Y. (2020). "Efficiency measurement and influencing factors of regional innovative green development in China," Science \& Technology Progress and Policy 37(3), 33-42.

Li, X., Sun, X., and Su, S. (2017). "Emissions reduction efficiency of sewage treatment services in county areas in China based on DEA-Tobit modeling," Resources Science 39(3), 451-460. DOI: 10.18402/resci.2017.03.07

Liang, S., and Luo, L. (2019). "The dynamic effect of international R\&D capital technology spillovers on the efficiency of green technology innovation," Science Research Management 40(3), 21-29. DOI: 10.19571/j.cnki.1000-2995.2019.03.003

Liu, J., Zeng, X., and Zeng, Q. (2019). "Influence of environmental regulation and government innovation subsidy on enterprise green product innovation," Research on Economics and Management 40(6), 106-118. DOI: 10.13502/j.cnki.issn10007636.2019.06.008

Liu, Z. (2019). "Forming an all-directional opening pattern and construction of a modern economic system in the new era," Journal of Central South University (Social Sciences) 25(2), 1-6.

MOF (2017). "Accounting standards for business enterprises no. 16 - government subsidies in 2017," (http://kjs.mof.gov.cn/zt/kjzzss/kuaijizhunzeshishi/ 200806/t20080618_46232.htm), Accessed 20170525.

NDRC (2019). "Guidelines on building a market-oriented green technology innovation system,” (https://www.ndrc.gov.cn/fzggw/jgsj/hzs/sjdt/201904/ t20190419_1130654.html), Accessed 20190415.

Porter, M. E., and Kramer, M. R. (2006). "Strategy and society: The link between competitive advantage and corporate social responsibility," Harvard Business Review 84, 78-91. 
Porter, M. E., and Linde, C. (1995). "Toward a new conception of the environmentcompetitiveness relationship," Journal of Economic Perspectives 9(4), 97-118.

Qi, S. Z., Zhang, Q., and Wang, B. B. (2017). "Market-oriented incentives to the innovation of new energy companies - Evidence from venture capital and companies' patents," China Industrial Economics 2017(12), 95-112.

Qian, L., Wang, W., and Xiao, R. (2018). "Research on the regional disparities of China's industrial enterprises green innovation efficiency from the perspective of shared inputs," China Population Resources and Environment 28(5), 27-39. (in Chinese)

Ramanathan, R. (2005). "An analysis of energy consumption and carbon dioxide emissions in countries of the Middle East and North Africa," Energy 30(15), 28312842. DOI: 10.1016/j.energy.2005.01.010

Schumpeter, J. (2000). "Theory of economic development," Beijing: The Commercial Press 2000, 73-74.

Sharma, S., and Thomas, V. J. (2008). "Inter-country R\&D efficiency analysis: An application of data envelopment analysis," Scientometrics 76(3), 483-501. DOI: 10.1007/s11192-007-1896-4

Shen, N. (2012). "Environmental efficiency, industrial heterogeneity and intensity of optimal regulation - Nonlinear test based on industrial panel-data," China Industrial Economics 2012(3), 56-68. DOI: 10.19581/j.cnki.ciejournal.2012.03.005

Sun, X., and Wang, Y. (2014). "The influence of firm size on productivity and its difference - Based on the empirical test of industrial firms in China," China Industrial Economics 28(5), 57-69.

Tobin, J. (1958). "Estimation of relationship for limited dependent variables," Econometrica 26(1), 24-36. DOI: 10.2307/1907382

Wang, K., Liu, Y., Shi, L., Lei, L., and Chen, Y. (2017a). "Yangtze River Economic Zone spatial and temporal disparities in industrial green water resource efficiency and influencing factors based on two-step analysis of EBM-Tobit Model," Resources Science 39(8), 1522-1534. DOI: 10.18402/resci.2017.08.09

Wang, W. X., Zuo, Z., and Zhang, J. J. (2017b). "Research on the impact of new media information disclosure on financing cost of private enterprises -- based on the empirical analysis of small and medium-sized board private listed companies," Friends of Accounting 2017(19), 128-136.

Wang, Y., Li, Y., Ma, Z, and Song, J. (2017c). "Media coverage, environmental regulation and corporate environment behavior," Nankai Business Review 20(6), 8394.

Xiao, R. Q., Song, Y., and Qian, L. (2019). "Research on spatial spillover effect of enterprises' green innovation output from the perspective of value chain in two stages," Finance and Trade Research 2019(4), 71-83.

Xiao, R. Q., Wang, Z. Z., Qian, L. (2015). "Research on Chinese enterprise's technology innovation efficiency and its influencing factors in different property based on the angle of value chain in the two stages," Journal of Industrial Engineering/ Engineering Management 29(02), 190-201.

Xing, H., Wang, F., and Gao, S. (2019). "Does government subsidize promote substant innovation of enterprises: A collaborative perspective of the dual attribute of resources and signaling," Modern Economic Research 20(3), 57-64. 
Xu, L. P., Xin, Y., and Zhu, J. G. (2011). "The close attention given by the media, and listed companies' performance of social responsibility," Management World 2011(03), 135-143+188.

Xu, M. (2017). Research on Green Technology Innovation Efficiency and its Influencing Factors of China's Large and Medium-Sized Industrial Enterprises, Master's Thesis, Anhui University of Finance and Economics, Bengbu, China.

Yang, D., Chen, H., and Liu, Q. (2017). "Media pressure and corporate innovation," Economic Research Journal 52(8), 125-139.

$\mathrm{Yu}, \mathrm{L}$. (2007). "Research on relationship between enterprise character and innovation efficiency," The Journal of Quantitative \& Technical Economics 24(5), 108-115.

$\mathrm{Yu}, \mathrm{Y}$. (2009). "Research on technological innovation efficiency and its influencing factors of China's high-tech industry," Economic Science 31(4), 62-74. DOI: 10.19523/j.jjkx.2009.04.006

Yuan, Y., and Xie, R. (2016). “Environmental regulation and the 'Green' productivity growth of China's industry," China Soft Science 23(7), 144-154.

Zhang, C., Guo, B., and Yu, T. (2015). "Pollution heterogeneity, optimal environmental regulation intensity and production technical progress," Science Research Management 36(3), 138-144. DOI: 10.19571/j.cnki.1000-2995.2015.03.017

Zhang, J., Yu, L., Bi, Q., and Pan, J. (2016). "Media supervision, environmental regulation and firm green investment," Journal of Shanghai University of Finance and Economics 18(5), 91-103. DOI: 10.16538/j.cnki.jsufe.2016.05.008

Zhao, L., and Zhang, L. (2020). "The impact of media coverage on enterprise green technology innovation: The moderating role of marketization level," Management Review 32(09), 132-141.

Zhu, J., Yu, P., and Shi, J. (2015). "Study on the relationship between green technical innovation, environmental performance, economic performance and governmental rewards and punishments: based on integrated supply chain," Forecasting 35(5), 6166.

Article submitted: May 19, 2021; Peer review completed: June 13, 2021; Revised version received and accepted: September 7, 2021; Published: September 29, 2021.

DOI: $10.15376 /$ biores.16.4.7648-7670 